\title{
Universiteit
}

Leiden

The Netherlands

\section{GYNOTEL: telephone advice to gynaecological surgical patients after discharge}

Caljouw, M.A.A.; Hogendorf-Burgers, M.E.H.J.

\section{Citation}

Caljouw, M. A. A., \& Hogendorf-Burgers, M. E. H. J. (2010). GYNOTEL: telephone advice to gynaecological surgical patients after discharge. Journal Of Clinical Nursing, 19(23-24), 3301-3306. doi:10.1111/j.1365-2702.2010.03395.x

Version: $\quad$ Not Applicable (or Unknown)

License: $\quad$ Leiden University Non-exclusive license

Downloaded from: https://hdl.handle.net/1887/117635

Note: To cite this publication please use the final published version (if applicable). 


\title{
GYNOTEL: telephone advice to gynaecological surgical patients after discharge
}

\author{
Monique AA Caljouw and Marja EHJ Hogendorf-Burgers
}

Aims and objectives. To investigate in surgical gynaecological patients the types of health problems arising or persisting up to six weeks after discharge and the effectiveness of telephone advice.

Background. The decreasing length of hospital stay has increased the need for specific instructions about the postdischarge period. Telephone advice could be a valuable tool to address this problem. To our knowledge, postdischarge health problems and the value of telephone advice have not been investigated among gynaecological patients.

Design. Randomised controlled trial.

Methods. Gynaecological patients expected to stay in the ward longer than 24 hour were invited to participate. A pilot study showed that wound healing, pain, mobility, urination, defecation and vaginal bleeding were the most common health problems postdischarge. Based on that information, guidelines were formulated that were used by trained nurses to give telephone advice to the intervention group $(n=235)$, in addition to the usual care. The control group of gynaecological patients $(n=233)$ received usual care only.

Results. Of all 468 participants, about 50\% were operated for general gynaecology. At discharge, wound pain (56\%), mobility problems $(54 \%)$ and constipation $(27 \%)$ were the most frequently mentioned problems in both groups. Participants who completely followed the advice with regard to wound healing $(p=0.02)$, pain $(p=0.01)$, vaginal bleeding $(p=0 \cdot 03)$ and mobility ( $p=0.04$ ) experienced greater improvement than participants who did not follow, or only partly followed, the advice. Conclusions. The telephone advice appears to make a significant contribution to help gynaecological surgical patients to solve or reduce their postdischarge health problems.

Relevance to clinical practice. The positive effect of such advice can be interpreted as an improvement in the quality of life of the postoperative gynaecological patient.

Key words: discharge, gynaecology, nursing, postoperative, quality of life, telephone advice

Accepted for publication: 3 June 2010

\section{Introduction}

The length of hospital stay after a surgical procedure has substantially decreased. Following major gynaecological surgery, a reduction from 7-10 days to three days or less in hospital is now common (Easton et al. 2003). Nowadays, although patients may need more information about the postdischarge period, nurses have insufficient time to prepare them for their discharge and recovery at home (Bubela et al.

Authors: Monique AA Caljouw, MSc, RN, Researcher, Department of Public Health and Primary Care, Leiden University Medical Center; Marja EHJ Hogendorf-Burgers, RN, Expert Nurse, Department of Gynaecology, Leiden University Medical Center, Leiden, The Netherlands
1990, Bowman et al. 1994, Bostrom et al. 1996). Generally, most patients experience the majority of health problems in the first week postdischarge and about 50\% seek help (Bowman et al. 1994). When telephoned by a nurse, it is reported that about $90 \%$ of surgical patients had health-related questions (Bostrom et al. 1996). Because the first week postdischarge seems most important regarding information about recovery, study on the effectiveness of telephone advice has been recommended (Bostrom et al. 1996). 
The informational needs of surgical patients are influenced by self-care deficits in the postdischarge period (Bubela et al. 1990). Especially, women appeared to need information and instructions related to daily activities. In addition, surgical patients (particularly after a short stay in hospital for major surgery) wanted instructions about deficits in daily activities at home; information about complications, wound care and pain also had high priority (Jacobs 2000).

Telephone consultations have been used to anticipate informational needs postdischarge, especially in the acute care setting and for follow-up of oncology patients (Coleman 1997, Cox \& Wilson 2003, Wahlberg et al. 2003). These consultations allow us to make an inventory of the main problems and offer the possibility of giving accurate advice. However, only when the telephone advice has been safely embedded in guidelines and the telephone calls made by nurses trained in 'good' communicative skills (both verbally and in writing), the consultation would be optimal and successful (Anastasia \& Blevins 1997, Coleman 1997, Alaily $\&$ Diab 2003). Others have recommended that the nurse making the call should be informed about the care plan of the patient (Bowman et al. 1994, Jacobs 2000). Patients who receive adjusted, specific and individually tailored information feel more satisfied and better informed about their condition (Henderson \& Zernike 2001, Theobald \& McMurray 2004, McMurray et al. 2007).

Our department has experienced an increasing number of incoming calls related to postoperative early discharge, mainly within one week after discharge. Telephone advice might be an effective way to supplement the provision of information to surgical patients after discharge (Bonhomme et al. 1995). Therefore, this study investigates the types of health problems experienced in the first six weeks postdischarge. Also investigated is the effectiveness of postdischarge telephone advice and patient satisfaction with this form of advice.

\section{Methods}

The study was conducted in patients admitted to the gynaecological department of a university hospital for a major surgical intervention between October 2004-June
2006. The local Medical Ethics committee approved the study. All patients provided written informed consent.

\section{Procedure}

Prior to the study, for eight weeks, the department secretary/ nurses registered 85 incoming telephone calls to establish health problems postdischarge. The most frequently occurring problems were related to wound healing, pain, mobility, urination, defecation and vaginal bleeding.

This randomised controlled trial has three data collection points (Fig. 1): at discharge (T1), during the postdischarge telephone call (T2) and at the closing outpatient visit six weeks postdischarge (T3). Participants were randomised to the intervention group or the control group. In addition to usual care, the intervention group received telephone advice within three to nine days after discharge. With just one telephone consultation a week, the minimum number of days between discharge and calling was three and the maximum was nine days. The duration of each telephone call was registered, as was the number of days after discharge that the call was made The control group received usual care consisting of a discharge talk with the gynaecologist and a follow-up outpatient appointment six weeks later.

The telephone intervention is based on guidelines containing decision levels for each frequently occurring health problem. The guidelines are based on nursing diagnosis (Carpenito-Moyet 2004), the seriousness of the problem and the nursing advice that might be given. This advice is based on the literature, the incoming calls registered in the pilot study and on daily practice. Four experts (two nurses and two gynaecologists) were consulted about the guidelines, which were adapted where necessary to reach consensus and ensure content validity.

Four experienced gynaecological nurses, involved in giving telephone advice, were trained to use the guidelines. Two training sessions were dedicated to the guideline manual followed by practical training in conducting interviews by means of role playing. This ensured uniformity in interview techniques and in giving structured and adjusted advice. At the closing outpatient visit, the control group was asked to

$\mathrm{T} 3$

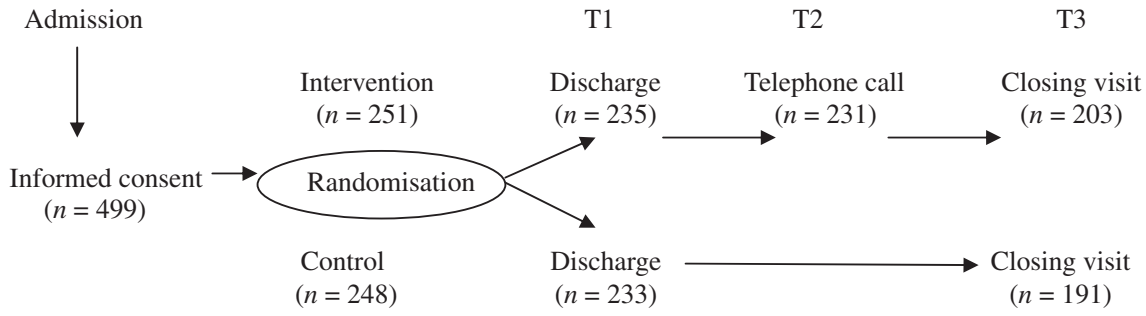

Figure 1 Study design and number of patients. 
complete a self-reported questionnaire about their health problems during the six weeks after discharge and any present complaints.

The intervention group was asked to complete the same self-reported questionnaire about their health, as well as a self-reported questionnaire about the effectiveness of the telephone advice and their opinion on/satisfaction with the telephone calls. Both questionnaires (on health and on telephone advice) were developed by the researchers and adapted after four experts (two nurses and two gynaecologists) had provided their feedback.

\section{Participants}

Recruitment of participants occurred preoperatively in the gynaecological outpatient clinic. Inclusion criteria for the study were age $\geq 18$ years, availability of a telephone, adequate comprehension of the Dutch language, planned admission for a gynaecological surgical procedure, stay at the ward $>24$ hour and an outpatient appointment six weeks after discharge. Patients visiting the wound consultant were excluded from the study.

\section{Data collection and statistical analysis}

Data were collected between October 2004-June 2006. Demographic information was obtained on age, surgical subgroup, length of hospital stay and health problems postdischarge. Descriptive statistics were used to summarise the demographical information. Chi-squared analysis was used for non-parametric data and $t$-tests for parametric data.

The incidence and severity of health problems were calculated. Comparison of the frequency of the health problems between the two groups was used to determine any differences between patients' experience of health problems. In the intervention group, a comparison was made between those completely, partly or not following the advice and improvement of health problems. The telephone call was evaluated with a self-reported questionnaire. The duration of each telephone call was registered (in minutes), and mean duration (and standard deviation; SD) of each call was calculated. Data were analysed with SPSS version 12.0 for Windows. For all analyses, a $p$-value $\leq 0.05$ was considered significant.

\section{Results}

\section{Response}

Of the 508 patients invited to participate, 499 agreed. Of these, 468 were eligible and finally 394 completed the study
(Fig. 1). The total response rate was $84.2 \%(86.4 \%$ for the intervention group and $82.0 \%$ for the control group). A total of 31 patients were not eligible for the following reasons: 19 had unexpectedly visited the wound consultant, five did not want to participate after randomisation, six did not meet the inclusion criteria (operation was delayed, or stay at the ward $<24$ hour, or no outpatient appointment after six weeks) and one patient was transferred to another hospital.

\section{Patient characteristics}

Table 1 shows that, in both groups, approximately $50 \%$ of the participants were operated for general gynaecology. There were no significant differences between the two groups in mean length of hospital stay, patient characteristics and the presence of health problems at discharge (Table 1).

\section{Health problems after discharge}

Table 2 shows the incidence of new health problems in the two groups postdischarge. Wound pain, mobility problems and constipation were frequently mentioned by both groups. There were no significant differences in health problems between the two groups; however, for mobility the intervention group had more problems compared to the control group $(p<0.001)$. Also, no significant differences in health problems were found between the surgical subgroups (data not shown).

\section{Effectiveness and evaluation of telephone advice}

The majority of participants (range: 65.4-82.8\%) reported that they followed the nurse's advice completely and experienced significantly more improvement than participants who did not (or only partly) followed the advice related to wound healing, wound pain, vaginal bleeding and mobility (Table 3 ). The telephone advice was evaluated positively by the participants with a mean score of 8.0 (on a $0-10$ scale, SD 1.34). Of all participants, $96.6 \%$ reported 'The nurse answered all my questions', $84.7 \%$ reported 'The advice of the nurse had a surplus value' and $61.6 \%$ reported 'After the advice I could take better care of myself at home' (Table 4). The duration of the telephone calls ranged from 3-30 minutes with a mean of $12 \cdot 3$ (SD 5.3) min.

\section{Discussion}

To our knowledge, this is the first follow-up study to evaluate the management of postdischarge health problems after gynaecological surgery, i.e. in a specific female group. 


\begin{tabular}{|c|c|c|c|c|c|}
\hline & $\begin{array}{l}\text { Intervention } \\
(n=235)\end{array}$ & $\begin{array}{l}\text { Control } \\
(n=233)\end{array}$ & $t$-test & $\chi^{2}$ & $p$-value* \\
\hline Age in years (mean, SD) & $50 \cdot 1(14 \cdot 6)$ & $47 \cdot 9(13 \cdot 0)$ & $1 \cdot 69$ & & $0 \cdot 09$ \\
\hline Surgical subgroups & & & & $4 \cdot 50$ & $0 \cdot 34$ \\
\hline General gynaecology & $112(47 \cdot 9)$ & $116(50 \cdot 0)$ & & & \\
\hline Oncology & $67(28 \cdot 6)$ & $71(30 \cdot 6)$ & & & \\
\hline Pelvic floor & $47(20 \cdot 1)$ & $32(13 \cdot 8)$ & & & \\
\hline Fertility & $6(2 \cdot 6)$ & $11(4 \cdot 7)$ & & & \\
\hline Other & $2(0 \cdot 9)$ & $2(0 \cdot 9)$ & & & \\
\hline $\begin{array}{l}\text { Length of hospital stay in days } \\
\text { (mean, SD) }\end{array}$ & $5 \cdot 4(3 \cdot 2)$ & $5 \cdot 2(3 \cdot 0)$ & $0 \cdot 72$ & & 0.47 \\
\hline \multicolumn{6}{|l|}{ Postdischarge health problems } \\
\hline Wound healing & $29(12 \cdot 3)$ & $26(11 \cdot 2)$ & & $8 \cdot 30$ & $0 \cdot 08$ \\
\hline Wound pain & $134(57 \cdot 3)$ & $130(57 \cdot 3)$ & & $5 \cdot 04$ & $0 \cdot 28$ \\
\hline Urination & $29(20 \cdot 4)$ & $46(20 \cdot 4)$ & & $6 \cdot 23$ & $0 \cdot 18$ \\
\hline Constipation & $65(27 \cdot 8)$ & $60(26 \cdot 3)$ & & $0 \cdot 70$ & $0 \cdot 95$ \\
\hline Vaginal bleeding & $74(32 \cdot 0)$ & $83(35.9)$ & & $3 \cdot 15$ & $0 \cdot 21$ \\
\hline Mobility & $126(54 \cdot 5)$ & $127(55 \cdot 0)$ & & $3 \cdot 29$ & $0 \cdot 51$ \\
\hline
\end{tabular}

Table 1 Patient characteristics at discharge

Values are numbers (\%) unless stated otherwise.

" $p \leq 0.05$ was considered significant.

Table 2 Incidence of postdischarge health problems in the intervention and control groups

\begin{tabular}{llllr}
\hline & Intervention & Control & $\chi^{2}$ & $p$-value* \\
\hline Wound healing & $20 \cdot 9$ & $19 \cdot 1$ & $0 \cdot 17$ & 0.680 \\
Wound pain & $53 \cdot 1$ & $48 \cdot 1$ & $0 \cdot 40$ & 0.527 \\
Urination & $34 \cdot 9$ & $31 \cdot 2$ & $0 \cdot 48$ & 0.489 \\
Constipation & $36 \cdot 9$ & $34 \cdot 1$ & $0 \cdot 23$ & 0.630 \\
Vaginal bleeding & $20 \cdot 8$ & $28 \cdot 4$ & 1.96 & $0 \cdot 161$ \\
Mobility & $74 \cdot 4$ & $47 \cdot 1$ & 13.4 & $<0.001$ \\
\hline
\end{tabular}

$* p \leq 0.05$ was considered significant.

Although the role of women has changed over the decades, most women are still responsible for the family and household (Bubela et al. 1990, Bonhomme et al. 1995). If women wish to maintain this role after discharge, there might be insufficient time for proper recovery. Especially with the decrease in hospital stay, women may need more detailed instructions about their daily activities at home (Jacobs 2000).

The present study confirms that problems with mobility (i.e. mechanical problems and deficits/imbalance in daily rest/ activity) were frequent in the first six weeks postdischarge. It was also found that significant improvement was made in mobility problems when the telephone advice was followed completely, i.e. the instructions from the nurse helped women to find a balance between their rest and activity pattern.

Hospital stay after surgical procedures has decreased, therefore, nurses are unable to anticipate all the informational needs of a patient at the time of discharge. Therefore, they need to be aware that patients who are discharged with little or no information are more likely to develop problems that require them to re-visit a health facility (Henderson $\&$ Zernike 2001).

Based on a Cochrane review, it was concluded that followup by telephone is feasible and is appreciated; however, it was unclear whether telephone follow-up is also effective in reducing postdischarge health problems (Mistiaen \& Poot 2006). Although some nurses assume that telephone advice can reduce or prevent problems postdischarge, this might be an erroneous or only partly attainable expectation. However, patients do at least have the opportunity to discuss their health problems during recovery with experienced nursing staff (Easton et al. 2003) and found such calls helpful (Hodgins et al. 2008).

To our knowledge, this is the first study to assess the value of structured telephone advice for gynaecological patients. The aim was to help patients manage their actual or potential postdischarge problems. The results show that most participants could handle their problems but experienced an improvement when the advice was followed. The positive effect found in the intervention group can therefore be interpreted as an improvement in the quality of life for these postoperative gynaecological patients.

In contrast, the control group received usual care only and no structured written or oral information from the nurses at discharge. Data on their health problems were collected at the closing visit six weeks postdischarge. Therefore, it remains unknown when these problems occurred; moreover, they may have forgotten some problems encountered shortly after discharge. In future studies, the control group could be asked keep a diary about health problems occurring during the first 
Table 3 Intervention group: comparison of those following the advice 'Not/Partly' or 'Completely' in relation to improvement of the postdischarge health problems

\begin{tabular}{llcccc}
\hline & Advice followed & $n(\%)$ & Improvement & $\%$ & $p$-value* \\
\hline Wound healing & Not/Partly & $11(17 \cdot 2)$ & $7 / 11$ & $63 \cdot 6$ & 0.02 \\
& Completely & $53(82 \cdot 8)$ & $48 / 53$ & $90 \cdot 6$ & \\
Wound pain & Not/Partly & $18(34 \cdot 6)$ & $11 / 18$ & $61 \cdot 1$ & 0.01 \\
& Completely & $34(65 \cdot 4)$ & $31 / 34$ & $91 \cdot 2$ & \\
Urination & Not/Partly & $8(19 \cdot 0)$ & $7 / 8$ & $87 \cdot 5$ & 0.60 \\
& Completely & $34(81 \cdot 0)$ & $27 / 34$ & $79 \cdot 4$ & \\
Constipation & Not/Partly & $16(29 \cdot 6)$ & $11 / 16$ & $68 \cdot 8$ & 0.30 \\
& Completely & $38(70 \cdot 4)$ & $31 / 38$ & $81 \cdot 6$ & \\
Vaginal bleeding & Not/Partly & $7(22 \cdot 6)$ & $3 / 7$ & $42 \cdot 9$ & 0.03 \\
& Completely & $24(77 \cdot 4)$ & $20 / 24$ & 83.3 & \\
Mobility & Not/Partly & $19(27 \cdot 1)$ & $14 / 19$ & 73.7 & 0.04 \\
& Completely & $51(72 \cdot 9)$ & $47 / 51$ & $92 \cdot 2$ & \\
\hline
\end{tabular}

*Chi-square test; $p \leq 0.05$ was considered significant.
Table 4 Evaluation of the telephone advice by the participants

\begin{tabular}{lr}
\hline & AGREE \\
\hline $\begin{array}{l}\text { It was pleasant to tell the nurse how I was getting on } \\
\text { after discharge }\end{array}$ & $182(97 \cdot 8)$ \\
The telephone call was not necessary & $24(13 \cdot 6)$ \\
The nurse answered all my questions & $172(96 \cdot 6)$ \\
The nurse gave specific advice on how to deal with & $152(88 \cdot 9)$ \\
my problems & $149(84 \cdot 7)$ \\
The advice of the nurse had a surplus value & $181(98 \cdot 9)$ \\
$\begin{array}{l}\text { The nurse had made enough time for the telephone } \\
\text { call }\end{array}$ & $11(6 \cdot 2)$ \\
After the telephone call I still had some questions \\
$\begin{array}{l}\text { After the advice I could take better care of myself at } \\
\text { home }\end{array}$ & $106(61 \cdot 6)$ \\
$\begin{array}{l}\text { If I am admitted to hospital again, I want to be } \\
\text { called by the nurse after discharge }\end{array}$ & $175(94 \cdot 6)$ \\
\hline
\end{tabular}

Values are numbers (\%) of positive responses.

week(s) after discharge; however, this is not part of 'usual care'.

The significant difference in 'mobility' between the two groups might be explained by the attention paid to the rest and activity patterns during the telephone advice.

The mean duration of a telephone consultation is reported to be 10-20 min (Bowman et al. 1994, Bostrom et al. 1996), whereas in the present study it was $12.3 \mathrm{~min}$. Although this is a substantial time investment, our patients were satisfied and experienced a surplus value in their quality of care. To improve self-management at home, the advice should be individually tailored to maximise its relevance for each patient. The format of the gynaecological guideline for telephone advice might be transferable to other surgical fields, but its cost-effectiveness may need to be established.

\section{Conclusions}

This study emphasises the importance of the provision of information postdischarge by telephone to gynaecological surgical patients by experienced nurses. If the advice is followed, it can make a significant contribution to help patients solve and reduce their postdischarge health problems. Telephone advice has proven beneficial for our postoperative patients and has been implemented in our department as a standard intervention at days 3-6 postdischarge. This type of advice might be suitable for other types of care facilities, following adjustment of the guidelines to fit the specific context of other patient groups.

\section{Relevance to clinical practice}

Nurses are well positioned to anticipate informational needs of women in the postdischarge period. Structured telephone advice is an important tool to discharged gynaecological surgical patients. Nurses can offer individualised care concerning postdischarge health problems and give specific advice how to deal with these health problems. The positive effect of such advice can improve the quality of life of the postoperative gynaecological patient.

\section{Contributions}

Study design: MC, MH; data collection and analysis: MC, $\mathrm{MH}$ and manuscript preparation: $\mathrm{MC}, \mathrm{MH}$.

\section{Conflict of interest}

There is no conflict of interest in relation to this article. 


\section{References}

Alaily A \& Diab Y (2003) Telephone gynaecological follow-up. Journal of Obstetrics and Gynaecology 23, 648649.

Anastasia PJ \& Blevins MC (1997) Outpatient chemotherapy: telephone triage for symptom management. Oncology Nursing Forum 24, 13-22.

Bonhomme S, Guerra C \& Nimijean W (1995) Telephone follow-up of gynecology day surgery patients. On line for quality and continuity of care. L'ifirmière de Quebéc 3, 10-16.

Bostrom J, Caldwell J, McGuire K \& Everson D (1996) Telephone follow-up after discharge from the hospital: does it make a difference? Applied Nursing Research 9, 47-52.

Bowman GS, Howden J, Allen S, Webster RA \& Thompson DR (1994) A telephone survey of medical patients 1 week after discharge from hospital. Journal of Clinical Nursing 3, 369-373.

Bubela N, Galloway S, McCay E, McKibbon A, Nagle L, Pringle D, Ross E \& Shamian J (1990) Factors influencing patients' informational needs at time of hospital discharge. Patient Education and Counseling 16, 21-28.

Carpenito-Moyet LJ (2004) Nursing Diagnosis. Application to clinical practice. Lippincott Williams \& Wilkins, Philadelphia.

Coleman A (1997) Where do I stand? Legal implications of telephone triage Journal of Clinical Nursing 6, 227-231.

Cox K \& Wilson E (2003) Follow-up for people with cancer: nurse-led services and telephone interventions. Journal of Advanced Nursing 43, 51-61.

Easton K, Read MD \& Woodman NM (2003) Influence of early discharge after hysterectomy on patient outcome and GP workloads. Journal of Obstetrics and Gynaecology 23, 271-275.

Henderson A \& Zernike W (2001) A study of the impact of discharge information for surgical patients. Journal of Advanced Nursing 35, 435-441.

Hodgins MJ, Ouellet LL, Pond S, Knorr S \& Geldart G (2008) Effect of telephone follow-up on surgical orthopedic recovery. Applied Nursing Research $21,218-226$.
Jacobs V (2000) Informational needs of surgical patients following discharge. Applied Nursing Research 13, 12-18.

McMurray A, Johnson P, Wallis M, Patterson E \& Griffiths S (2007) General surgical patients' perspectives of the adequacy and appropriateness of discharge planning to facilitate health decision-making at home. Journal of Clinical Nursing 16, 1602-1609.

Mistiaen P \& Poot E (2006) Telephone follow-up, initiated by a hospital-based health professional, for postdischarge problems in patients discharged from hospital to home. Cochrane Database Systematic Reviews 4, CD004510.

Theobald K \& McMurray A (2004) Coronary artery bypass graft surgery: discharge planning for successful recovery. Journal of Advanced Nursing 47, 483491.

Wahlberg AC, Cedersund E \& Wredling R (2003) Telephone nurses' experience of problems with telephone advice in Sweden. Journal of Clinical Nursing $12,37-45$. 